九州大学学術情報リポジトリ

Kyushu University Institutional Repository

The Effect of Farm Size on Agricultural Intensification and Resource Allocation

Decisions : Evidence from Smallholder Farms in Embu District, Kenya

Oduol, Judith Beatrice Auma

Graduate School of Bioresource and Bioenvironmental Sciences, Kyushu University

Tsuji, Masao

Faculty of Agriculture, Kyushu University

https://doi.org/10.5109/4683

出版情報: 九州大学大学院農学研究院紀要. 50 (2)，pp.727-742，2005-10-01. Faculty of Agriculture, Kyushu University

バージョン：

権利関係 : 


\title{
The Effect of Farm Size on Agricultural Intensification and Resource Allocation Decisions: Evidence from Smallholder Farms in Embu District, Kenya
}

\author{
Judith Beatrice Auma ODUOL ${ }^{1}$ and Masao TSUJI*
}

\author{
Laboratory of Farm Management, Division of International Agricultural Resource Economics \\ and Business Administration, Department of Agricultural and Resource Economics, \\ Faculty of Agriculture, Kyushu University, Fukuoka 812-8581, Japan \\ (Received June 30, 2005 and accepted July 26, 2005)
}

\begin{abstract}
There has been a phenomenal decline in the average farm size in Kenya, especially in the high and medium agricultural potential areas, following rapid population growth coupled with traditional land inheritance patterns. This paper highlights how smallholders in Embu District have adjusted their farming practices and resource allocation decisions to meet the increasing demand of producing more output from small farms. We postulate that as farm sizes become small, thus precluding the possibilities of increasing output through area expansion, farmers are confronted with two options: first, renting an additional land, and second, intensifying agricultural production by adopting land-saving technologies as well as diversifying into high value crops that yield greater revenue per unit of land and labour.

In this paper we have divided the sample households into three categories (small, medium and large farms) based on operational holding size in order to illustrate how adjustments in farming practices and resource allocation decisions vary with farm size.

Our findings indicate that as land constraints intensify, farmers exhibit a high degree of agricultural intensification as manifested in their inclination towards land use practices that aim at increasing land use efficiency. Moreover, as land scarcity continues to pervade the study region, the tendency to increase output through area expansion (hiring in additional land) is supplanted by the use of modern productivity enhancing inputs that increase output per unit area at less costs. Further, our data show that, on the whole, smaller farms depict a higher level of intensification than the relatively larger farms, although the relationship between land scarcity and intensification is not linear, possibly due to financial constraints which engender selective adoption and partial implementation of innovations. Notably, where land resources were limiting, cash crops appeared to compete with food staples for both land and modern inputs (fertilizer and pesticides).
\end{abstract}

\section{INTRODUCTION}

Land is arguably the most important asset in the rural areas of most developing countries, because it is not only the primary means of generating livelihood but often the vehicle for investing and accumulating wealth. Land is therefore an invaluable resource to most developing countries whose economies hinge on agriculture. Over the years, African countries have been thought to be land- abundant and that labour was the only resource considered to be limiting (Helleiner 1975; Eicher 1982; Mellor, 1985). In deed,

\footnotetext{
${ }^{1}$ Laboratory of Farm Management, Division of International Agricultural Resource Economics and Business Administration, Department of Agricultural and Resource Economics, Graduate School of Bioresource and Bioenvironmental Sciences, Kyushu University

* Corresponding author (E-mail: mtsuji@agr.kyushu-u.ac.jp)
} 
until recently, many technologies developed for African countries, for instance draught power, were tailored to save labour and thus facilitate the opening up of more land. There is ample evidence, however, that the rapid rate of population growth and the insufficient absorption of labour by non-agricultural sectors in a number of sub-Saharan African countries have led to a decline in the frontier (Hayami and Ruttan, 1985).

Studies indicate that approximately a third of sub-Saharan African countries have already closed the frontier; a third is in transition; and a third is still land- abundant (Reardon et al., 1996). Delgado et al. (1987) concede that land suitable for high value cash crops- usually perennial tree crops tends to be in shorter supply than arable land, and that this point was most likely reached in East African coffee areas decades ago. In Kenya, for example, annual growth rate in land under arable and permanent crops was 1.1 percent in 1969-1979, but declined to 1 per cent in the period 1999-2001 (FAOSTAT, 2004). And in Embu district, the area under coffee has stagnated at around 8,000 hectares, increasing only marginally by year (GOK, 1996).

It is therefore apparent that in the high agricultural potential regions of Kenya, where land has become overwhelmingly the scarcest resource, the need for technological change is not only driven by the need to increase agricultural productivity but also by the need to intensify production on a shrinking resource base.

In view of the rapidly declining farm sizes, farmers have to make drastic adjustments to their farming practices if they have to keep pace with the increasing demand to produce more output from less land. A number of changes are likely to take place as farmers try to adjust to land scarcity. First, there may be out migration to marginal areas when land in high potential areas is no longer accessible, a phenomenon that may be curtailed by public policy towards land use or by ethnic and cultural barriers (Uma Lele and Stone, 1989). Alternatively, a more feasible but perhaps short- lived means of expanding land under cultivation such as renting an additional land may emerge.

Second, as the possibilities of renting in land or moving out to marginal areas become increasingly limited, farmers may adopt land saving techniques. One such technique that more or less occurs spontaneously in response to land scarcity concerns changes in cropping patterns. Boserup $(1965,1981)$ asserts that as the population density increases, changes occur in cropping techniques, which include shortening fallow periods, increasing the number of cropping cycles as well as cropping intensity. But, changes in cropping patterns alone may not necessarily result in increased output per unit area if they are not accompanied by soil fertility management practices. Instead, cropping the soil intensively only leads to nutrient mining, which in turn reduces land and labour yields.

The third option, although another land saving technique, emphasises the need to incorporate soil fertility management practices and the need to substitute crops that use the same land and labour but yield greater revenue. These two options, however, do not bring about increased productivity unless they are exploited properly. In other words, in the face of declining farm sizes, the ability of land-constrained farmers to achieve increased agricultural productivity hinges on their ability to make an efficient choice among alternative paths. Soil fertility management practices, however, are only necessary, but not sufficient means for increasing land productivity and must therefore be combined with the use of high-fertilizer responsive crop varieties and a shift to high value crops, which give high returns but require less land and labour. 
The objective of this paper is to highlight the adjustments in farming practices that have been adopted by farmers in Embu district in response to land scarcity. In particular, we have attempted to address the aforementioned objective by posing the following questions: (1) Does land scarcity axiomatically lead to agricultural intensification? (2) Does the type of intensification adopted vary with farm size? (3) How does land and modern input allocation decisions vary with farm size and crop type?

\section{METHODOLOGY}

The data used in this paper are derived from a cross-sectional household survey conducted in 2004 over smallholder mixed farms in Embu district. The original sample consisted of 120 households, although 9 households were dropped from the analysis because of inconsistency in the data. Besides, two out of the nine households did not have coffee enterprise, while the remaining seven households had abandoned coffee plantations and thus no costs or returns were reported for the enterprise. As a result, the findings of this study are based on a stratified random sample of 111 households drawn from three of the five administrative divisions of Embu district (Nembure, Kyeni and Runyenjes).

For empirical analysis, we concentrated on only one agro-ecological zone, the Upper midland 2 (UM2), which is also the main coffee zone. Focusing on one region is expected to reduce the wide variation in farming practices and land constraints observed at national level. More importantly, concentrating on one region reduces price variation, an important consideration given our assumption that all farms face the same prices.

The main purpose of the survey was to obtain information on costs and amounts of inputs used in crop production. Data were collected on crop enterprises undertaken on the farm in short rains 2003, and included physical quantities and prices of inputs used in the production process. On average, the sample households cultivate 8 different types of crops in a season. An average of 4 food staples, 4 perennial/cash crops and 1 vegetable crop is grown on the farm. Food staples include maize, beans, Irish potatoes, sweet potatoes, cassava, yams and arrow roots, while cash crops consist of coffee, tea, bananas, macadamia, passion fruits and avocado. In addition, a small proportion of the respondents (32\%) cultivate vegetables, such as kales, tomatoes, cabbage, carrots and onions. In particular, data were collected on two principal crops (maize and coffee) and three subsidiary crops (beans, Irish potato and vegetables).

In an attempt to demonstrate how the uptake of innovations and the type of adjustments adopted by the households in response to land scarcity are influenced by farm size, we have divided the respondents into three proportional groups based on operational holding size'. The three categories of farms, herein referred to as "small, medium and large farms", have an average operational holding size of $0.44 \mathrm{ha}, 0.99$ ha and $1.98 \mathrm{ha}$ respectively.

A point noteworthy is that in Kenya, land and statistical records define smallholdings

1 Operational holding size encompasses both rented and owned land under coffee, maize, beans, potatoes and vegetables

${ }^{2}$ Farm households grouped under Small, medium and large farms operate holdings ranging from 0.2-0.55 ha, 0.55-1.0 ha and 1.0-3.25 ha, respectively. 
as farms less than twelve hectares, although the definition varies from one region to another depending on the degree of land scarcity and the agricultural potential of the land (GOK, 2003). Thus, despite its name, the largest quartile in our study area still falls under the category of smallholdings by national definition. Grouping of the households according to operational holding size is deemed valuable in providing an insight into the understanding of how response to land scarcity varies across different farm size categories. Further, operational holding size, as opposed to ownership holding size was preferred as a measure of size of the business because of the presence of a number of part-owners (31\%). Failure to take into account the amount of land borrowed by the households would underestimate the costs on the one hand and overestimate the returns on the other hand.

\section{RESULTS AND DISCUSSION}

\section{Introduction}

In land-abundant agrarian economies, production needs can be wholly met from owned holding. By contrast, where population pressure has diminished farm land, the size of owned holding may be insufficient to produce enough income to meet the needs of the farm family. In such circumstance, it may be necessary to increase the size of the business by the following methods: renting an additional land and intensifying the production of crops. Besides, when working capital is limiting, a condition that characterises most smallholder farms, readjustment in land allocation decisions in order to create more space for the preferred crops may be prevalent. In this section, we provide evidence of the significance of these three methods in alleviating land constraints in our study site and demonstrate how the choice of each method is influenced by farm size.

\section{Renting land}

Renting an additional land seems to be the only feasible method by which land constrained households in Embu district, where traditional patterns of land inheritance and informal land markets have diminished landholdings, can gain control of larger quantities of land without having to commit money needed to buy land. Besides, owing to the high capital requirements needed for efficient farming, renting land can be a good way to exploit the benefits of a larger operation without taking on large amounts of debts. Alternatively, farmers who own sufficiently large farms may be motivated to rent in land by the desire to minimize risks of crop failure or to exploit agro-ecological diversity. While the latter option offers greater flexibility to farmers whose farms may be located on poor soils or in agro-ecological zones that cannot support a wide a range of crops, it is yet to be exploited in the study region, where farm sizes have become so small that the need to increase farm size seems to take precedence over spreading risks.

The results show that on average, the sample households own around one hectare of land, but cultivate slightly more than one hectare (table 1). The distribution of landholdings, however, is skewed with more than half of the households owning less than one hectare of land. Households own holdings ranging from 0.04 hectares to 4.8 hectares. Therefore, renting land seems to be the only option available to households with very small holdings if they have to realize the greatest long term income for the family. 
Table 1. Average size of landholding by farm size category

\begin{tabular}{lccc}
\hline Farm size category & \multicolumn{3}{c}{ Average size in hectares } \\
\cline { 2 - 4 } & $\begin{array}{c}\text { Operational } \\
\text { holding }\end{array}$ & Owned & Rented \\
\hline Small $(n=37)$ & 0.44 & $0.38(86 \%)$ & $0.06(14 \%)$ \\
Medium $(n=37)$ & 0.99 & $0.83(84 \%)$ & $0.16(16 \%)$ \\
Large $(n=37)$ & 1.98 & $1.93(97 \%)$ & $0.05(3 \%)$ \\
Total $(\mathrm{N}=111)$ & 1.14 & $1.05(91 \%)$ & $0.09(9 \%)$ \\
\hline
\end{tabular}

Source: Survey 2004

The findings indicate that on average 31 percent of the households rented in land, with the households owning less than 0.5 hectares of land accounting for 41 percent of the renters. 38 percent of the renters were from the middle category, while only 14 percent belonged to the large farm size category. Further, the study revealed that the proportion of land rented in varied vastly among the households. It was observed that the proportion of land rented in as a share of owned holding averaged 95 percent for the renters although the figure ranged from a minimum of 14 percent to a maximum of 500 percent, suggesting that some respondents relied exclusively on rented land. Nevertheless, only 14 percent of the households rented in land amounting to more than 50 percent of their own holdings. The data reinforce the notion that renting in land in the region occurs as a response to the need to expand cultivable land, as indicated by 94 percent of the renters.

Striking in our findings is that despite nearly 60 percent of the sample households owning less than one hectare of land, the results suggest that renting in of land is less prevalent in the region. The proportion of land rented in by farmers in different categories of farms is presented in table 1 . The table shows that on average 91 percent of the operational holding size was owner-operated. Yet a look at the relationship between ownership holding size and the proportion of land rented in suggests that farmers operating small and medium size farms rented in relatively more land than those with large holdings. Another important observation is the marginal difference in the proportion of land rented in by the households in the small and the medium farm categories. Thus, the evidence points to the conclusion that the decision to rent in land is not only governed by the size of owned holding, but is indeed an interplay between a number of factors within the farmers' environment.

First, in an area where population pressure has taken its toll on the size of farm land, the value of land may be high and the land market so competitive that potential tenants would have less power to negotiate for better rental terms. In this case, the potential tenants will weigh the benefits of renting in land against other possibilities for increasing output. The decision to rent in land will thus depend on the margin between the rent and the value of marginal productivity of land. Moreover, since small farmers are usually averse to risks, they are more apt to pursue other alternative methods of increasing output that give reliable returns.

Since agriculture in the study region is exclusively rainfed, with virtually no irrigation facilities to mitigate risks of crop failure due to vagaries of weather, bringing an extra land into cultivation at an extra cost may be unacceptable to the farmers who are already over- 
burdened by the high costs of variable inputs, especially if the undertaking is perceived to be unprofitable. Under such condition, production will be geared towards satisfying household food requirements, in which case the land -constrained households will strive to maximize output from their own land regardless of whether or not the size is sufficiently large to utilize efficiently their labour and capital.

The second factor which may be critical in determining the amount of land rented in by households is the availability of farm land for rental, which in turn, depends on the ability of non-cropping sectors to absorb part of the farming population in order to free up land for expansion. At the same time, whether or not prospective tenants will gain access to the available farm land hinges on the willingness of the landlords to lease out their land. From an economic standpoint, farmers who find opportunities outside farming will only be motivated to lease out their land if the prevailing rent exceeds the cost of leaving the land idle. Yet, in certain circumstances the behaviour of economic agents may deviate from economic theory, for instance, in the case of asymmetric information about the tenants' ability to make productive use of the land. In Kenya, where lease agreements are for the most part verbal, landlords may have little assurance that tenants will employ sound farming practices on their land. As a result, landlords may opt to leave the land idle or lease it out to friends or relatives. This behaviour may lead to rationing of rental land and thus result in unproductive use of land.

The results indicate that only 3.6 per cent of the respondents rented out land, of which 50 per cent rented out land to friends and relatives. Given that only a few respondents rented out land signifies scarcity of rental land and thus points to the conclusion that renting an additional land in itself may not be a long-term solution to land scarcity in the region. Moreover, the large proportion of sample households (77\%) dependent exclusively on agriculture suggests that very little farm land may be available for renting. Furthermore, renting land from the neighbouring districts, another viable option, may be rendered unfeasible by the cost of transporting inputs and output onto the farm and the time spent en route, which reduce profit margins. In fact, the results provide evidence of the respondents' preference for farms in the vicinity of their domiciles, as indicated by the entire sample households' inclination to rent farms within the district.

In summary, factors such as limited freedom in the production plans that characterize tenancy system, location of rental land, which may sometimes be at the periphery, and unavailability of appropriate land for rental, which may compromise timeliness of operations, are likely to dissuade smallholders from renting an additional land. Also, a multiplicity of different factors, such as lack of sufficient working capital, which reduce the ability of land-constrained households to pay for land in the rental market; imperfections in the land rental market; and risk averse behaviour of small farmers due lack of insurance markets, may compel smallholders to adopt relatively inefficient insurance substitutes to enable them to deal with unexpected productivity shocks. For instance, farmers may choose to operate relatively small farms, and instead adjust their crop and asset portfolios to a low return, low risk combination that reduces their vulnerability. Moreover, land allocation decisions may be altered in favour of a more liquid asset such as grain, which even though less productive would provide them with greater security in case of subsistence risk. 


\section{Land allocation decisions}

In general, our findings indicate that the sample households have a strong tendency to allocate more land to subsistence crops ${ }^{3}$. Table 2 presents the mean acreage and proportion of land allocated to crops by farm size category. The table shows that on average, the sample households allocate approximately half of their holding to subsistence crops, with the greatest proportion (30\%) being allocated to maize. Further, the results suggest that the proportion of land allocated to maize is almost equal across the three farm size categories. Yet in absolute terms, households in the highest land quartile allocate the largest amount of land to maize. Striking in the data, however, is the small proportion (24\%) of land allocated to coffee despite being the major cash crop in the region. An in-depth examination of the data reveals that households in the lowest land quartile allocated a relatively larger proportion of land to coffee than did households in the middle and the highest quartiles, but in absolute terms, households in the highest quartile allocated more land to coffee than households in the lowest quartile. On average, households in the highest land quartile allocated three times as much land to coffee as did households in the lowest quartile. Thus, the data suggest a positive relationship between land size and the size of land allocated to coffee (perennial crops).

The observed relationship between farm size and the proportion of land allocated to subsistence (grains) and cash crops is consistent with other findings elsewhere that in subsistence priority systems, the food requirements of the family tend to dominate resource allocation and the starchy staple is usually the largest enterprise (Mellor et al., 1987). But a more relevant question that merits further discussion is why smallholders accord great importance to producing their own food, yet cash cropping programs are thought to spur productivity by providing cash for improved inputs. Moreover, cash crops open avenues for increased market contact and exchange, which are prerequisites for farm development. Some of the underlying reasons for this behaviour include price volatility due to seasonal variations in yields and uncertainty about coffee payments.

Table 2. Proportion of land allocated to various crops by farm size category

\begin{tabular}{lcrrrrrrr}
\hline \multirow{2}{*}{ Crops } & \multicolumn{2}{c}{ Small } & \multicolumn{2}{c}{ Medium } & \multicolumn{2}{c}{ Large } & \multicolumn{2}{c}{ Total } \\
\cline { 2 - 9 } & $\begin{array}{l}\text { Size } \\
\text { (ha) }\end{array}$ & $\begin{array}{r}\text { \% of } \\
\text { total }\end{array}$ & $\begin{array}{l}\text { Size } \\
\text { (ha) }\end{array}$ & $\begin{array}{r}\text { \% of } \\
\text { total }\end{array}$ & $\begin{array}{l}\text { Size } \\
\text { (ha) }\end{array}$ & $\begin{array}{r}\text { \% of } \\
\text { total }\end{array}$ & $\begin{array}{r}\text { Size } \\
\text { (ha) }\end{array}$ & $\begin{array}{r}\text { \% of } \\
\text { total }\end{array}$ \\
\hline Maize & 0.13 & 30 & 0.31 & 31 & 0.60 & 30 & 0.34 & 30 \\
Beans & 0.06 & 14 & 0.15 & 16 & 0.30 & 15 & 0.17 & 15 \\
Potatoes & 0.04 & 9 & 0.06 & 6 & 0.13 & 7 & 0.08 & 7 \\
Vegetables & 0.01 & 2 & 0.02 & 2 & 0.01 & 0.5 & 0.01 & 1 \\
Coffee & 0.16 & 36 & 0.23 & 23 & 0.46 & 23 & 0.28 & 24 \\
Others & 0.04 & 9 & 0.22 & 22 & 0.48 & 24 & 0.26 & 23 \\
\hline
\end{tabular}

Source: Survey 2004

\footnotetext{
${ }^{3}$ Subsistence crops in this case refer to maize, beans, potatoes and vegetables since they are mainly cultivated for consumption although the surplus generated from the crops is sometimes sold to meet household expenses. The total acreage under the four crops is contrasted with that under coffee, the major cash earner for the households.
} 
Table 3. Proportion of land allocated to crops by farm size category and type of tenure

\begin{tabular}{lccccccccc}
\hline \multirow{2}{*}{ Crops } & \multicolumn{2}{c}{ Small } & \multicolumn{2}{c}{ Medium } & \multicolumn{2}{c}{ Large } & \multicolumn{2}{c}{ Total } \\
\cline { 2 - 9 } & $\begin{array}{c}\% \\
\text { owned }\end{array}$ & $\begin{array}{c}\% \\
\text { rented }\end{array}$ & $\begin{array}{c}\% \\
\text { owned }\end{array}$ & $\begin{array}{c}\% \\
\text { rented }\end{array}$ & $\begin{array}{c}\% \\
\text { owned }\end{array}$ & $\begin{array}{c}\% \\
\text { rented }\end{array}$ & $\begin{array}{c}\% \\
\text { owned }\end{array}$ & $\begin{array}{c}\% \\
\text { rented }\end{array}$ \\
\hline Maize & 70 & 30 & 70 & 30 & 93 & 7 & 85 & 15 \\
Beans & 83 & 17 & 83 & 17 & 97 & 3 & 88 & 12 \\
Potatoes & 75 & 25 & 67 & 37 & 92 & 8 & 88 & 12 \\
Vegetables & 100 & 0 & 100 & 0 & 100 & 0 & 100 & 0 \\
Coffee & 100 & 0 & 100 & 0 & 100 & 0 & 100 & 0 \\
\hline
\end{tabular}

Source: Survey 2004

Because producer prices of coffee are usually pegged to the world market prices, farmers may receive insufficient cash for food purchases if a glut of coffee on the world market develops during harvest time. As a result, smallholders tend to devote resources to food production to guard against a worse than average year.

Aside from the desire to attain food self-sufficiency, another factor, which may be significant in explaining the differences in the amount of land allocated to cash and subsistence crops, is the type of tenure. Table 3 shows variations in the proportion of land allocated to crops by type of tenure. The table reveals the households' marked preference to plant rented plots with subsistence crops. This could be attributed to the fact that in land -scarce countries, land suitable for high value cash crops, which are for the most part perennial tree crops, tends to be in short supply; hence the cost of gaining access to such land may be prohibitive. In addition, in Kenya written lease agreements are less frequent; under such condition tenants have few incentives to undertake long-term investments unless they are certain that they will recoup the value of the investment during the rental term. Furthermore, owing to limited opportunities in the non-cropping sector, the landlords also depend on the same land for their livelihood, and may be reluctant to rent out land for a long duration. In this respect, insecurity and the shortness of tenure of rented farms may deter farmers from planting them with perennial crops such as coffee, which have a long gestation period.

Given that cultivation of coffee can only be undertaken on owned holdings suggests that the proportion of land under coffee will undoubtedly decline as farm sizes become small, a phenomenon, which may have serious implications for farm productivity.

In short, given the shrinking resource base, land allocation decisions will continue to be governed by the need to cushion the family against subsistence shocks as long as the uncertainty that surrounds coffee proceeds and food prices persists. On the basis of these findings, it appears that changes in land allocation decisions must be accompanied by intensification of agricultural production (land saving techniques) if complementarity benefits that have been reported to exist between food crops and cash crops are to be fully exploited.

\section{Intensifying the production of crops}

Intensification of crop production is yet another strategy by which households with limited access to additional land, either through purchase or renting, can augment their 
output, thereby mitigating land constraints. In our study region, we identified a number of land saving techniques that have emerged in response to land scarcity. These techniques are classified into two categories namely, 'traditional' and 'modern' techniques based on the way they are developed. While traditional techniques emerge spontaneously as more land is cropped more frequently in response to land scarcity, the development of modern techniques and their subsequent uptake by the end-users require massive investment in both human and physical infrastructure. Included under traditional methods are techniques aimed at, but not restricted to, increasing land use efficiency such as reduced fallow periods, multiple cropping and intercropping. Modern techniques, on the other hand, entail the use of biological and chemical inputs such as high yielding crop varieties, fertilizers and pesticides. Shifts to high value crops (enterprise switching), another option deemed valuable in hastening the transition from subsistence to commercial agriculture, is also discussed under traditional techniques although successful adoption of such techniques hinges on policy and incentives, effected through price signals.

'Thus, the ability of land constrained households to realize increased farm productivity is hypothesised to be contingent on their capability to make an efficient choice among the two alternative paths (traditional versus modern, or a combination of the two). More importantly, the decision as to which land saving technique to embrace among the two alternative pathways is postulated to be conditioned by the relative scarcity of land and capital in addition to other social and economic factors. In view of declining farm sizes, this paper argues that the uptake of a combination of both traditional and modern techniques is a prerequisite for increased productivity. In this section, we provide empirical evidence of how the choice between traditional and modern land saving techniques (type of intensification) varies with the degree of land scarcity.

\section{Traditional land saving techniques}

The most common method of maintaining adequate soil moisture and achieving soil conservation in traditional systems has been to alternate cropping with long bush fallow cycles. Due to population pressure, however, these systems have given way to shorter grass fallows and in some areas continuous cultivation. Furthermore, restoring soil fertility through rotational systems that depend on a fallow period has become unfeasible as starchy staples continue to occupy a high proportion of cultivated land. Because shortening of fallow periods entails very minimal costs, it is the most rudimentary form of intensification that will almost invariably develop in response to land scarcity. In our study sample, for example, virtually all the land was under cultivation, as indicated by the small percentage (14\%) of respondents who reported having left their land under fallow for a period of between six months and one year. Likewise, evident from the results is the decreasing role of fallow periods as a method for maintaining soil nutrient balance, especially in the small farm size category, where fallow periods have been completely replaced with continuous cultivation. Of the 14 percent who had their land under fallow, 40 percent belonged to the middle farm size category, while 60 percent were from the large farm size category. Nevertheless, none of the respondents in the lowest land quartile had their under land fallow, indicating the increasing demand for farm land.

Intensity of land use as measured by the ratio of land under crops (excluding fallow) to the total land available (operational holding size) was found to vary with farm size. On 
average, 88 percent of the total holding was planted with crops, although the value was much higher in the small farm size category, where 95 percent of the total holding was under crops, while the values for the middle and the large farm size categories were was 87 and 83 percent respectively.

Thus, it can be deduced from the results that as land becomes scarce and farms grow smaller, farmers shorten fallow periods thereby making more intensive use of their land.

\section{Mixed cropping and Intercropping}

Another important finding is the households' inclination towards land use patterns that aim at increasing efficiency of land use, such as multiple cropping. Multiple cropping has long been used by farmers in Embu district to diversify their investment portfolios against production and price risks. Lately, however, it has been widely adopted as a strategy to increase yields in the face of declining holdings.

Moreover, since multiple cropping entails increasing the number of cropping cycles per year, it can enable resource requirements, for example labour and management, to be distributed evenly throughout the agricultural season, thereby enhancing the productivity of a resource. Multiple cropping exists in different facets and may involve the cultivation of two crops (for annual crops) or more (for vegetable crops) in a year. In the study region, however, the cropping pattern has been synchronized with the bimodal rainfall pattern, giving rise to two cropping seasons in a year. As a result, the practice of multiple cropping per se cannot be regarded as a new strategy that has evolved as a result of land scarcity. Instead, the significance of multiple cropping in alleviating land constraints is seen in the context of mixed cropping and intercropping, which are the most relevant aspects of multiple cropping discussed in this paper.

Mixed cropping has become an indispensable means by which land constrained farmers can increase crop output per unit area without necessarily incurring additional costs on hiring land. Table 4 shows the average number of crop types grown by the sample households in a season. While the results indicate a tendency to diversify crop mix as farm sizes diminish, mixed cropping appears to be scale neutral, as shown in table 4 . The data show that the sample households cultivate an average of eight types of crops in a season, with the average for the small and the large farm size categories ranging between seven and nine crops, respectively. The marginal difference in the average number of crop types cultivated by the respondents in the three farm size categories highlights the growing demand for more farm land in the region, which has compelled farmers in the three categories to intensify cultivation. At the same time, it may be an indication of an attempt by the households to minimize production risks that characterize rainfed agriculture.

Although the major premise behind crop diversification strategy is to ensure stable and maximum earnings, the extent to which maximum earnings can be realized through multiple cropping hinges on the availability of supplemental water, labour, working capital as well as access to support services (research and extension). In our study site, where farming is exclusively dependent on rainfall patterns, lack of irrigation has been a major hindrance to diversification into high value crops such as vegetables.

As shown in table 4, the three farm size categories display a tendency for food staples and cash crops, in which case an average of around four types of food staples and cash crops are cultivated per season as compared to only one type of vegetable crop. 
Table 4. Average number of crops grown per season by type and farm size

\begin{tabular}{lcccc}
\hline \multirow{2}{*}{ Crop category } & \multicolumn{4}{c}{ Farm size category } \\
\cline { 2 - 5 } & Small & Medium & Large & Total \\
\hline Food staples (grains, pulses, tubers and roots) & 3.5 & 3.7 & 4.0 & 3.7 \\
Cash crops (tree crops, fruits and nuts) & 3.3 & 3.7 & 3.8 & 3.6 \\
Vegetables & 0.7 & 0.9 & 0.9 & 0.8 \\
Total & 7.0 & 8.0 & 9.0 & 8.0 \\
\hline
\end{tabular}

Source: Survey 2004

This is attributable to the fact that in rainfed conditions, unlike in irrigated systems, farmers have to carefully adjust the choice of crops to the weather. The limited flexibility of rainfed agriculture forces farmers to grow a limited number of crops regardless of the market prospect for these crops relative to other crops. Thus, in the context of our study area, crop choice appears not to be strictly governed by economic considerations alone but also by other factors such as food self sufficiency and the crops' adaptability to harsh weather conditions. But the tendency to diversify into traditional crops such as coffee and cereals which have been shown to exhibit low income elasticities of demand and hence reduced benefits to farmers is worrying and may have serious consequences for the productivity of the farms. In this case, the source of low productivity may stem largely from allocative inefficiency owing to the choice of crops with low marketed value.

Inasmuch as lack of irrigation facilities seems to play a major role in delaying the shift to high value crops, the degree of land scarcity which ostensibly dictates the type of cropping system is another significant factor. Our findings reveal that where farm sizes are relatively small, as in the study region, intercropping is the main method by which farmers accomplish intra-seasonal diversification. Figure 1 shows that intercropping is commonly practiced among all the three farm size categories, although it is more predominant in the small farm size category.

Further, the data indicate that the practice is more prevalent on maize, beans and coffee than on vegetables and potatoes. Because intercropping requires careful planning by taking into account the soil, climate and crop varieties, the inability of vegetable crops to co-exist with traditional crops (coffee and cereals) in an intercropping system tends to dissuade farmers from growing them. It is for the same reason that food staples and cash crops tend to constitute the greatest proportion of crops cultivated by households in the small farm size category, as illustrated in figure 2. The data reinforce the proposition that small farmers are generally less responsive to techniques or innovations that require massive changes in their traditional practices (Mellor, 1987).

In conclusion, changes in land use associated with agricultural intensification are beneficial, notably, those designed to increase land use efficiency such as mixed cropping and reduced fallows. It is important to note however that, these practices lead to working the soil intensively to an extent that the short term or medium run increases in production that are usually realized often mask a real decline in productivity.

Moreover, resource constraints and incompatibility of certain crops (high value crops) with the traditional land saving techniques, for instance intercropping engender irrational decision making, which may result in allocative inefficiency. All this justifies the 


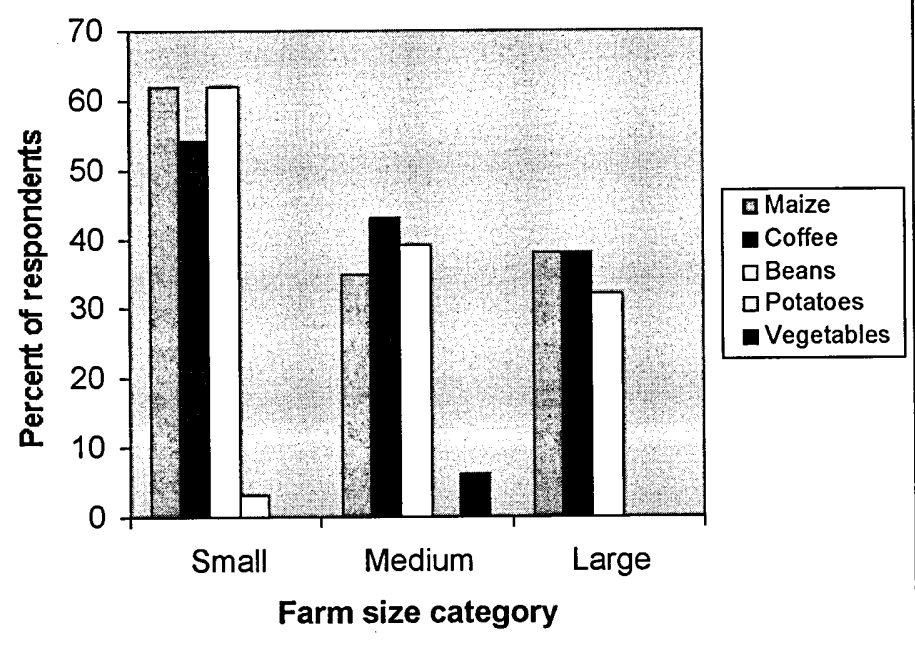

Fig. 1. Proportion of respondents practicing intercropping on selected crops Source: Survey 2004

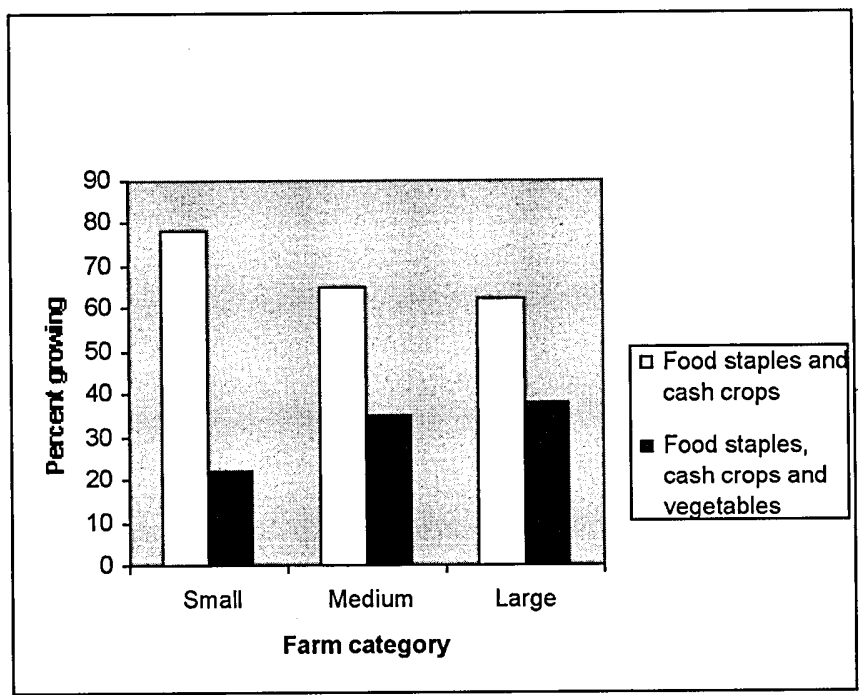

Fig. 2. Variation in crop combination by farm size category Source: Survey 2004 
need for a more superior technology that can offset the shortcomings of traditional techniques.

\section{Modern land saving techniques}

When land becomes absolutely scarce and complementary (modern land saving) inputs become less costly relative to land, future development of small farmers depends on the use of productivity enhancing inputs such as high yielding seed varieties, fertilizers, and pesticides.

Table 5 shows how the proportion of respondents using modern inputs varies with farm size and crop type. The data depict a strong association between farm size and the uptake of modern technologies, albeit the trend appears to vary with input and crop type. The results indicate that the proportion of respondents using fertilizer is higher on maize than on coffee. Similarly, a look at the variations in the level of uptake of the three modern inputs (fertilizer, pesticide, and hybrid seed in case of maize) reveals that in maize enterprise, chemical fertilizers are by far the most purchased variable input, possibly due to their immediate impact on yields. Although the proportion of respondents using fertilizer on maize is the same for the three farm size categories, there is a marked difference in the proportion using pesticides and hybrid seed. The proportion of respondents using pesticides and hybrid seed is higher on large farms than on small farms. The converse is true in the case of coffee enterprise where the level of uptake of pesticides is slightly higher than that of fertilizer.

An examination of how the level of fertilizer use varies with farm size reveals that the relationship is inverse for maize and potatoes but positive for coffee, beans, and vegetables. The results illustrating how the level of fertilizer use varies with farm size and crop type are given in table 6 . On the whole, the level of fertilizer use is 43 percent higher on

Table 5. Proportion of respondents using modern inputs by farm size and type of crop

\begin{tabular}{lccccc}
\hline \multirow{2}{*}{ arm size } & \multicolumn{3}{c}{ Maize } & \multicolumn{3}{c}{ Coffee } \\
\cline { 2 - 5 } & Fertilizer & Pesticides & Hybrid seed & Fertilizer & Pesticides \\
\hline Small & $97 \%$ & $27 \%$ & $54 \%$ & $24 \%$ & $32 \%$ \\
Medium & $97 \%$ & $46 \%$ & $68 \%$ & $27 \%$ & $32 \%$ \\
Large & $97 \%$ & $35 \%$ & $70 \%$ & $30 \%$ & $35 \%$ \\
Total & $97 \%$ & $36 \%$ & $64 \%$ & $27 \%$ & $33 \%$ \\
\hline
\end{tabular}

Source: Survey 2004

Table 6. Levels of fertilizer use by farm size and type of crop

\begin{tabular}{lcccccc}
\hline \multirow{2}{*}{ Farm size } & \multicolumn{5}{c}{ Amount of fertilizer in kilograms per hectare } \\
\cline { 2 - 7 } & Maize & Beans & Potatoes & Coffee & Vegetables & Mean \\
\hline Small & 189 & 4.4 & 160 & 6.2 & 7.9 & 96 \\
Medium & 151 & 4.6 & 207 & 6.4 & 28.5 & 95 \\
Large & 108 & 5.1 & 125 & 15.5 & 39.3 & 67 \\
Mean & 149 & 4.7 & 162 & 8.2 & 24.4 & 84 \\
\hline
\end{tabular}

Source: Survey 2004 
small farms than on large farms. The data show that small farms apply nearly twice as much fertilizer on maize as large farms do. Yet an assessment of the level of fertilizer use on coffee shows a totally different scenario; large farms apply three times as much fertilizer on coffee as small farms do. The same is true for vegetable and beans enterprise, in which the level of fertilizer use is higher on large farms than on small farms.

Also, the study shows that while the implementation of fertilizer innovation is almost uniform on large farms, small and medium farms display selective use of improved inputs. According to the data, small and medium farms fertilized only 21 and 47 percent of their operational holding respectively, compared to 90 percent in the large farms.

Thus, three main conclusions can be drawn from these findings with respect to the uptake and use of improved inputs (1) with the exception of beans, fertilizer use is generally higher on food crops than on cash crops (coffee) (2) land scarcity spurs investment in improved inputs, but innovations are generally implemented on only part of the holdings, indicating that financial resource constraint is a major concern (3) although maximum yields are reported to be achieved only when modern complementary inputs (fertilizers, pesticides and high yielding maize seeds) are simultaneously applied, farmers display an inclination to use fertilizer on crops.

The following questions can be posed based on the above conclusions: (1) why the tendency to use modern inputs on food crops is more pronounced in small farms than in large farms (2) why small farms apply innovations on only part of the holdings (3) why there is selective uptake of innovations

While the concept of agricultural intensification emphasizes the central role of modern inputs in enhancing farm productivity, the importance of organic manure to resourcepoor farmers in maintaining soil moisture and fertility and sometimes acting as a substitute for chemical fertilizers cannot be underrated. It is therefore important to examine how manure use varies with farm size and crop type, as this may be instrumental in explaining why farmers prefer to use modern inputs on food crops. Table 7 indicates that on average, small farms use more organic manure than do large farms.

Besides, the data show that both small farms and large farms apply more manure on coffee than on food crops, although the quantity applied on coffee increases with farm size. Since manure is, for the most part, obtained from owned livestock, farmers consider it as free and its marginal cost to them is zero, hence they tend to use it on crops whose returns they perceive to be less certain and long-term. On the other hand, in the cultivation of food crops which have a short maturity period and thus a relatively less risky

Table 7. Variations in levels of organic manure use by type of crop and farm size category

\begin{tabular}{lcccccc}
\hline \multirow{2}{*}{ Farm size } & \multicolumn{5}{c}{ Amount of organic manure in tonnes per hectare } \\
\cline { 2 - 7 } & Maize & Beans & Potatoes & Coffee & Vegetables & Mean \\
\hline Small & 3.10 & 0.60 & 3.50 & 4.60 & 0.74 & 3.10 \\
Medium & 1.30 & 0.13 & 2.30 & 5.80 & 0.90 & 2.00 \\
Large & 1.40 & 0.06 & 2.20 & 6.10 & 0.62 & 2.10 \\
Mean & 1.90 & 0.20 & 2.60 & 4.80 & 0.75 & 2.40 \\
\hline
\end{tabular}

Source: Survey 2004 
venture, small farms are more apt to use modern inputs whose marginal cost they consider to be higher than the freely available organic manure.

Also, farmers may be reluctant to use organic manure on rented plots, which are invariably planted with food crops, because of its long-term effects on the soil. Moreover, the bulkiness of manure may deter farmers from using it on rented plots, which may sometimes be located at the periphery, making transportation difficult and expensive. It therefore appears that when small farmers are confronted by resource constraints, short-term expediency tends to dominate their decision making. In such circumstance, food self-sufficiency and risk aversion tend to take precedence over other objectives in resource allocation decisions. In deed, existing literature confirms that farmers are generally more receptive to innovations that are highly profitable and increase the reliability of food (Mellor et al., 1987).

Another reason could be that small farms have land constraints and hence apply improved inputs on food crops to free land for cash crops. This probably explains why small farmers were able to devote a larger proportion of their operational holding to coffee than medium and large farms.

The underlying reason for selective adoption and implementation of complementary inputs could be lack of information regarding the drawback of using improved inputs in isolation, inasmuch as financial constraints play a major role in accentuating the practice. Because small farms have to hire in additional land, their dissipating wealth leaves them with few resources with which to purchase sufficiently large amounts of inputs for the whole farm. Moreover, due to financial constraints, farmers weigh the benefits of technologies presented to them based on the extent to which the technology addresses their immediate needs.

Besides, since maize seeds can be obtained from the previous seasons' harvest and pesticides are usually applied only when symptoms of pest attack are beyond economic threshold, fertilizers are usually given the first priority in decisions regarding the uptake of modern inputs. In this respect, farmers opt for technological packages that are tailored to improve soil conditions, because they perceive soil fertility replenishment as the most pressing need.

\section{CONCLUSION}

In general, our findings show that as land constraints intensify, farmers exhibit a high degree of agricultural intensification, as manifested in their inclination to land use practices that aim at increasing land use efficiency. Moreover, as land scarcity continues to pervade the region, the tendency to increase output through area expansion (hiring in additional land) is supplanted by the use of modern productivity enhancing inputs that increase productivity per unit area at less costs.

But the relationship between land scarcity and agricultural intensification appears not to be linear, since factors such as financial constraints appear to engender selective adoption and partial implementation of innovations, which may negate the benefits of intensification.

Furthermore, in cases where land resources were limiting, as in the small farm category, cash crop farming competed with food crops for both land and variable inputs. 
On the whole, the sample households depicted a tendency to allocate more resources to subsistence crops with short gestation periods, indicating that when farmers are confronted by resource constraints, food sufficiency and risk aversion tend to dominate their resource allocation decisions.

\section{ACKNOWLEGDEMENTS}

The author is deeply indebted to Professor Masao Tsuji (head of the laboratory of Farm Management, Kyushu University), Associate professor Dr. Hotta Kazuhiko and Assistant professor Dr. Shoji Shinkai for their invaluable comments on this paper.

\section{REFERENCES}

Boserup, E. 1965 The conditions of Agricultural Growth. The Economics of Agrarian Change under Population Pressure. New York: Aldine Publishing Company.

1981 Population and Technological Change: A Study of Long-Term trends. Chicago: The University of Chicago Press.

Delgado, C. L. and, C. G Ranade. 1987 Technological Change and Agricultural Labour Use. In: "Accelerating Food Production in Sub-Saharan Africa", ed. by J. W. Mellor, C. L. Delgado, and M. J. Blackie. The Johns Hopkins University Press, Baltimore and London

Eicher, C. K. 1982 Facing Up to Africa's Food Crisis. Foreign Affairs 61 (Fall)

FAOSTAT (United Nations Food and Agriculture Organisation Statistical Database). 2004 FAO Trade and Production Statistics. On -line available at http://apps.fao.org/

Hayami Y. and W. V. Ruttan. 1985 Agricultural Development: An International Perspective. The Johns Hopkins University Press, Baltimore and London.

Helleneir, G. K. 1975 Smallholder Decision-making: Tropical African Evidence. In: "Agriculture in Development theory", ed. by L. G. Reynolds. New Haven: Yale University Press.

Mellor, J. W. 1985 Technological Change in Low Labour Productivity, Land surplus developing economies: An Asian and African comparison. International Food Policy Research Institute, Washington, D. C.

Mellor, J. W., C. L. Delgado and M. J. Blackie. 1987 Accelerating food production in Sub-Saharan Africa. International Food Policy Research Institute. The Johns Hopkins University Press, Baltimore and London.

Reardon, T., V. Kelly, T. Jayne, K. Savadogo, and D. Clay. 1996 Determinants of Farm productivity in Africa: A Synthesis of Four Case Studies. Department of Agricultural Economics and the Department of Economics, Michigan State Lansing, Michigan, U.S.A. Online available at msu.edw/agecon/fs2/papers.pdf

Republic of Kenya . 1996 District Statistics office, Embu Unpublished material 2003 Statistical Abstract. Central Bureau of Statistics. Ministry of Planning and National Development. Government printer, Nairobi, Kenya.

Uma Lele, J. and W. S. Stone. 1989 Population Pressure, the Environment, and Agricultural Intensification. Variations on the Boserup Hypothesis. Madia discussion paper 4. Washington, D. C.: World Bank. 